\title{
Pragmatism vs interpretivism in qualitative information systems research
}

\author{
Göran Goldkuhl
}

Linköping University Post Print

N.B.: When citing this work, cite the original article.

This is the authors' version of the original publication:

Göran Goldkuhl, Pragmatism vs interpretivism in qualitative information systems research, 2012, European Journal of Information Systems, (21), 2, 135-146.

http://dx.doi.org/10.1057/ejis.2011.54

Copyright: Palgrave Macmillan

http://www.palgrave-journals.com/pal/index.html

Postprint available at: Linköping University Electronic Press

http://urn.kb.se/resolve?urn=urn:nbn:se:liu:diva-76528 


\title{
Pragmatism vs. interpretivism in qualitative information systems research
}

Göran Goldkuhl, \{goran.goldkuhl@liu.se\},

Department of Management and Engineering, Linköping University, Sweden

\begin{abstract}
Qualitative research is often associated with interpretivism, but alternatives do exist. Besides critical research and sometimes positivism, qualitative research in information systems can be performed following a paradigm of pragmatism. This paradigm is associated with action, intervention and constructive knowledge. This paper has picked out interpretivism and pragmatism as two possible and important research paradigms for qualitative research in information systems. It clarifies each paradigm in an ideal-typical fashion and then conducts a comparison revealing commonalities and differences. The possibilities of combining pragmatism and interpretivism in qualitative research in information systems are analysed. A research case that combines interpretivism and pragmatism is used for illustration. The paper thus contributes to a discussion about different paradigms and methods for qualitative research in information systems.
\end{abstract}

Key words: Qualitative research, interpretivism, pragmatism, paradigm, information systems

\section{Introduction}

\section{Background}

The interest in qualitative research in information systems (QRIS) has grown for several years. Many scholars acknowledge the difficulties in reducing the complex social and technical phenomena in the IS-field to quantitative figures. There is a need for more open and nuanced ways to study and analyse IS complexities. Historically, significant compilations of articles discussing and presenting qualitative IS research have been made, such as Mumford et al (1985), Nissen et al (1991), Lee et al (1997), Trauth (2001) Myers \& Avison (2002a) and Kock (2007). There have also been special issues in journals containing papers on qualitative research or certain methods within such a tradition; cf. e.g. Myers \& Walsham (1998), Kock \& Lau (2001), Baskerville \& Myers (2004).

One important discussion concerning QRIS is whether qualitative research is equal to interpretive as this has sometimes been considered the case. Trauth (2001b, p 7) states that "interpretivism is the lens most frequently influencing the choice of qualitative methods", There are however some reservations to make against such views. Myers \& Avison (2002b, p 5) write "It should be clear from above that the word 'qualitative' is not synonym for 'interpretive'. Qualitative research may or not be interpretive, depending on the underlying philosophical assumptions of the researcher." They mention three possible epistemologies (interpretive, positivist, critical) following Orlikowski \& Baroudi (1991) and Chua (1986).

The question of positivism vs. interpretivism in IS has been discussed by several scholars. Some attempts have been made to reconcile the differences and propose integrated views (e.g. Lee, 1991; Weber, 2004; Fitzgerald \& Howcroft 1998). Other scholars claim and insist that the differences between these two paradigms are great and irreconcilable (e.g. Orlikowski \& 
Baroudi, 1991; Walsham, 1993, 1995). It seems actually that much of the discussions and comparisons concerning interpretivism vs. positivism have had the character of interpretivists claiming the differences and positivists disregarding the differences. If one wants to discuss the differences between positivism and interpretivism in connection with qualitative research, it is obvious that interpretivism is an established, elaborated and adapted research paradigm for this type of research. Even if positivism can be applied to qualitative studies (e.g. Benbasat et al, 1987), ideal-typically it seems to have been adapted for use within quantitative studies.

Is it so that interpretivism should be seen as the dominant research paradigm for qualitative research? Are there, then, no real competitors? Alternative research paradigms which can be compared and evaluated together with interpretivism do exist. Critical research is one such paradigm according to a division made by Chua (1986) and Orlikowski \& Baroudi (1991), although there are scholars (e.g. Butler, 1998) who prefer to see this paradigm as a variant within interpretivism. On the basis of these discussions and comparisons I do not see an urgent need to proceed with making comparative reviews of interpretivism and critical research.

As stated, a major part of the meta-scientific debate has concerned the two rivals interpretivism and positivism. In a paradigm analysis within business ethics, Wicks \& Freeman (1998) have added pragmatism as a third alternative besides interpretivism and positivism. A similar stand has been taken by Fishman (1999) in psychology. Inspired by Wicks \& Freeman (1998), Goles \& Hirschheim (2000) also argue that also the IS research paradigm debate should include pragmatism.

Pragmatist thinking has influenced IS research to a great extent, although the paradigmatic foundations have not been fully acknowledged. When introducing the MIS Quarterly special issue on action research (AR), Baskerville \& Myers (2004) claim that paradigmatic foundations for this research approach should be found in pragmatism. Actually, they explicitly refer to the classical pragmatist philosophers (Pierce, James, Dewey and Mead) when making this statement. Far from everyone applying AR makes such a paradigmatic reference to pragmatism. Another evolving research approach within IS, design research (DR), can also be located within pragmatic ground. Lee \& Nickerson (2010) state that pragmatism is a more adequate research paradigm for design research than positivism.

Pragmatism is concerned with action and change and the interplay between knowledge and action. This makes it appropriate as a basis for research approaches intervening into the world and not merely observing the world. This would be the case if the intervention is organisational change (as in action research) or building of artefacts (as in design research). The growing interest in action research and design research (e.g. Cole et al, 2005; Järvinen, 2005; Iivari \& Venable, 2009) makes it important to investigate pragmatism as one possible paradigmatic base for QRIS.

Braa \& Vidgen (1999) have presented a research-methodological framework consisting of three epistemological orientations: Research 1) aiming for explanation and prediction, 2) aiming for interpretation and understanding and 3) aiming for intervention and change. The first approach is of course located within positivism and the second in interpretivism. For the third they do not give any clear reference to a corresponding school of thought. They refer to inventionary research and action research as variants of research for this epistemological 
orientation. Braa \& Vidgen (1999) is a typical example of researchers who talk about action and change oriented research without explicitly locating it within a pragmatist paradigm.

Braa \& Vidgen (1999) propose a research method, action case research, which combines interpretive and interventionary research. There are other scholars who also have identified an affinity between change and interpretation in research (e.g. Baskerville, 1999). Action research (ibid) and specialities as action case research (e.g. Braa \& Vidgen, 1999), grounded action research (Baskerville \& Pries-Heje, 1999) and dialogical action research (Mårtensson $\&$ Lee, 2004) all seem to comprise qualitative, interpretive and pragmatist research orientations.

\section{Purpose and procedure}

Certain scholars advise against blending interpretivism and positivism; instead recommending that they should be kept apart as separate research paradigms. How should one view pragmatism and interpretivism as paradigms? Should they be kept apart or could they be blended? Some hybrid forms have already been alluded to above. Do we understand the grounds for mixing pragmatism and interpretivism in QRIS sufficiently? Are there reasons for not adding pragmatist thinking to interpretive studies or vice versa?

If one follows the quest for pragmatism in IS research by Goles \& Hirschheim (2000), and other scholars (e.g. Goldkuhl, 2004; 2008b; Marshall et al, 2005), there seems to be a need for more comparative evaluations between research paradigms within IS that include pragmatism. Is pragmatism to be seen as suitable paradigm for qualitative research? If so, how is it related to interpretivism? What similarities and differences can be found? These research questions constitute the core of the current inquiry. Goles \& Hirschheim (2000) have taken an important first step here, comparing positivism, interpretivism and pragmatism. A more thorough investigation is, however, seriously required.

The purpose of the paper is thus to clarify characteristics of interpretivism and pragmatism as possible research paradigms for qualitative research within information systems. The purpose is to make a comparative review of these two research paradigms. Similarities and differences are sought for. The clarification and comparison will be made with the aid of paradigmatic constituents such as assumptions concerning ontology, epistemology, methodology and researcher - practice relations (Orlikowski \& Baroudi, 1991; Goles \& Hirschheim, 2000; Iivari, 2007). As a first step, the possible divergences need to be clarified. To do this I will conduct an ideal-typical approach in order to achieve clarification of each research paradigm. In this sense I will follow similar approaches which compare different research paradigms as ideal-types (e.g Orlikowski \& Baroudi, 1991). In their analysis of the three research orientations Braa \& Vidgen (1999) describe both the distinct research orientations and hybrids as mixtures between the "genuine forms". Initially in my own analysis I will try to elaborate ideal-typical genuine forms and avoid hybrid forms. A second step will be to investigate similarities and clarify the possibilities to combine the two research paradigms in practice. In connection with this I will also use an account of an empirical research project which comprises both interpretive and pragmatist elements.

For this paradigm comparison between interpretivism and pragmatism, what can be learnt from the debate concerning interpretivism vs. positivism? There are purist arguments claiming that paradigms should not be mixed; they should be kept apart as distinct approaches. There are, on the contrary, opponents against ideal-typically discerning of differences. To 
contrast research paradigms is seen as a hindrance of blending different approaches in practice. Goles \& Hirschheim (2000) even state that the introduction of pragmatism "undercuts the traditional dichotomistic warfare between conflicting paradigms by providing a philosophical basis grounded in pluralism". I do not think that researchers firmly rooted within one research paradigm (positivism or interpretivism) agree to this radical proposal. We have not yet come to an end of paradigm history in IS.

There are differences between research paradigms and I cannot see that such differences should be blurred. The identification of such differences contributes to our paradigmatic awareness. This is also a pre-condition for an informed mixing of views and elements from different research paradigms in practical research. There are arguments for discerning differences and similarities but also for investigating possibilities to blend and combine. My aim is to bring more clarity to the choice of qualitative research methods in IS: I want to reduce uncertainty among IS scholars as to whether it is possible to combine interpretive and pragmatist approaches in QRIS. This is especially important in regard to the growing interest in action research and design research in IS.

There are several reasons for bringing pragmatism into a comparative review of research paradigms for QRIS. Pragmatism may contribute with the broadening of possible research alternatives for a qualitative researcher; to see that interpretivism is not the main viable option. The bringing in of pragmatism may also contribute with clarifications of pure and hybrid forms of interpretivism and pragmatism in QRIS. One additional reason is that there are qualitative researchers that apply action research and/or design research who may wish to subscribe to a clear paradigmatic basis for their work.

\section{Interpretivism in qualitative research}

\section{Main characteristics}

Interpretivism is not a unified and unequivocal tradition. There are many forms of interpretivism. Butler (1998) identifies several different variants such as conservative, constructivist, critical and deconstructionist. The deconstructionist approach seems equivalent with postmodern structuralism and this approach does not appear to be central in the interpretive IS tradition. As indicated above, a critical tradition can be seen as a viable separate tradition within IS (cf. e.g. Orlikowski \& Baroudi, 1991) and this approach is therefore also left out from the current study. In my analysis I will mainly focus on the constructivist tradition and partially on the conservative (such as classical hermeneutics). This means that the analysis here will focus on hermeneutic and phenomenological traditions. My attempt is also, as mentioned, to make an ideal-typical account of interpretivism in IS.

The aim of understanding the subjective meanings of persons in studied domains is essential in the interpretive paradigm. This was a central claim in the Verstehen sociology of Max Weber (1978): the postulate of subjective interpretation. Alfred Schutz (1970) brought the Verstehen sociology further with inspiration from phenomenology. He claimed that scientific knowledge (concerning social life) was of second-order character. It must be based on the meanings and knowledge of the studied actors. "The constructs involved on common-sense experience of the intersubjective world in daily life... are the first-level constructs upon which the second-level constructs of the social sciences have to be erected" (ibid p 274). Silverman (1970) describes the difference between natural scientists and social scientists as being that they work with different realms. The natural world of matter is meaningless until the scientist 
imposes his meaning-constructs upon it. The social world of people is however full of meaning. It is built upon subjective and shared meanings. Silverman summarizes the differences in the following way: "Social life, therefore, has an internal logic which must be understood by the sociologist; the natural scientist imposes an external logic on his data." (ibid p 127).

The core idea of interpretivism is to work with these subjective meanings already there in the social world; i.e. to acknowledge their existence, to reconstruct them, to understand them, to avoid distorting them, to use them as building blocks in theorizing.

I will now leave the great sociologists who have formulated the basics of interpretivism and move on to those who have brought these ideas into IS research. Boland $(1985,1991)$ made early contributions to this area when explicitly using phenomenological and hermeneutic approaches. He states that "phenomenology is a preferred approach for the study of information systems... because... it is a way of study that respects the intentionality of actors, the symbolic nature of language and universal hermeneutic problem" (Boland, 1985 p 200). Other important contributors to interpretivism in IS are Orlikowski \& Baroudi (1991), Walsham (1993; 1995; 2006) and Klein \& Myers (1999) and I will study some of their arguments below.

\section{Constructivist ontology}

Interpretivism is dependent on constructivist ontology. This is explicated by Orlikowski \& Baroudi (1991 p 14) in the following way: "Ontologically, interpretive information systems research assumes that the social world (that is, social relationships, organisations, division of labours) are not 'given'. Rather the world is produced and reinforced by humans through action and interaction". The authors explicitly refer to "social relationships, organisations, division of labours" as elements of the world; i.e. letting relations be the essential parts. The authors describe the ontological elements elsewhere slightly different: "The aim of all interpretive research is to understand how members of a social group, through their participation in social processes, enact their particular realities and endow them with meaning, and to show how these meanings, beliefs and intentions of the members help to constitute their actions" (ibid p 13). In this ontological description cognitive elements ("meanings, beliefs and intentions") seem to be pivotal. This cognitive orientation is also emphasised when the authors describe the intentions of researchers to "understand the actors' views of their social world and the role in it" (ibid p 14; my emphasis). It is interesting to note that the world does not seem consist of objects in this constructivist view. In the above quotes, no objects can be found and in another quote, they explicitly refute 'objects': "The world is not conceived of as a fixed constitution of objects..." (ibid p 13).

Walsham (1993) describes the aim and scope of IS studies to produce "an understanding of the context of the information system, and the process whereby the information system influences and is influenced by its context" (ibid p 4f, emphasis in original). It is to be noted that the object of IS is not considered to be essential in Walsham's scoping of IS research knowledge; it is rather the context of IS and the dialectical relations between IS and context.

\section{Understanding through interpretation}

Ontology and epistemology are intertwined in interpretivism because knowledge (understanding, meanings) is so essential in the ontological assumptions of the constitution of 
the world. I will now move on to issues of more distinct epistemological character. The main character of IS research knowledge is an understanding through processes of interpretation. The researchers are supposed to interpret the "existing meaning systems shared by the actors" (Orlikowski \& Baroudi, 1991 p 15). Klein \& Myers (1999) have described a set of principles for interpretive field studies. These principles are derived from hermeneutics, phenomenology and anthropology and are intended to support the creation a hermeneutically based understanding. The primary principle is "the fundamental principle of the hermeneutic circle". Their interpretation of this principle (there exist other interpretations in literature) is the backand-forth movement between the whole and its parts. This can be seen as a contrast to positivistic studies which seem to work with a fixed set of variables. In an interpretive study it is essential to create a holistic understanding of the studied area; not only an understanding of its different parts. The understanding should emerge through dialectical movements between the holistic understanding and the understandings of singular parts. According to the authors, this principle is foundational for all interpretive work and it is also a basis for the other six principles.

I will not go through all the other principles, but just comment upon two of them. The second principle is the "principle of contextualization". The key idea is to create a re-constructive understanding of the social and historical context of the studied area. The authors claim that it is important "that the intended audience can see how the current situation under investigation emerged" (ibid p 73). This emphasis of historic emergence is an obvious trace from hermeneutics. It is interesting to note their contextualistic orientation towards historic background and emergence. This can partially be contrasted to Madill et al (2000 p 9) who describe contextualism to be "the position that all knowledge is local, provisional, and situation dependant".

\section{Researchers' relations to the practice field}

One of the interpretive principles (from Klein \& Myers) is concerned with the relation between researcher and practitioner: "the principle of interaction between the researchers and subjects". It is notable that this principle is concerned with the interaction between researcher and researched subjects during data generation. It is emphasised that the researched subjects ("the participants") are interpreters and co-producers of meaningful data. This implies that empirical data generation is seen as a process of socially constructed meanings; i.e. socially constructed by researchers and participants (cf. e.g. also Walsham, 1995). As mentioned, this principle is only concerned with the interaction between researcher and practitioner during the generation of empirical data. The authors do not say anything concerning interaction (knowledge transfer and use) in situations outside the empirical study. There is little said about the value of the created knowledge. They say that "interpretive researchers are...interested in... using theory more as a 'sensitizing device' to view the world in a certain way" (Klein \& Myers, 1999 p 75). This is also consistent with what Walsham (1993 p 6) says about truth in relation to scientific knowledge: "In the interpretive tradition, there are no correct and incorrect theories but there are interesting and less interesting ways to view the world". Interpretive research aims at knowledge as understanding and a purpose is that it should be interesting to audiences.

Many interpretive researchers seem to work rather close to the practice field which may imply engagement in the studied practices. Orlikowski \& Baroudi (1991) state that "the researcher can never assume a value-neutral stance". This can be contrasted with what Schutz (1970) says about the researcher-role in relation to the empirical practices. Alfred Shutz, as one of the 
key figures in interpretive sociology, distinguishes between practical vs. cognitive interests in the world. The researcher "is not involved in the observed situation, which is to him not of practical but merely of cognitive interest" (ibid p 275). He continues to say that the researcher "looks at [the observed situation] with the same detached equanimity with which the natural scientist looks at the occurrences in his laboratory" (ibid). The attitude of the researcher is characterized as "a mere disinterested observer of the social world" (ibid). It can be assumed that several contemporary interpretive IS researchers do not conceive themselves as detached and disinterested observers and thus object to this as an unfair characterisation. This is one example of the diversity in views within interpretivism.

\section{Pragmatism in qualitative research}

\section{Main characteristics}

Pragmatism as a research paradigm in this context is mainly concerned with what has been called American pragmatism, as it emerged through the writings of Peirce, James, Dewey and Mead among others. Pragmatic thinking is however not restricted to this American tradition. As described by for example Arens (1994) and Thayer (1981), there are resemblances and connections to many European thinkers. There are also clear resemblances with East-Asian thinking (Shusterman, 2004).

The essence of a pragmatist ontology is actions and change; humans acting in a world which is in a constant state of becoming. Blumer (1969 p 71) claims that "the essence of society lies in an ongoing process of action - not in a posited structure of relations. Without action, any structure of relations between people is meaningless. To be understood, a society must be seen and grasped in terms of the action that comprises it". Actions are thus pivotal in pragmatism, but not for their own sake. Action has, as Dewey (1931) states, the role of an intermediary. Action is the way to change existence. To perform changes in desired ways, action must be guided by purpose and knowledge. The world is thus changed through reason and action and there is an inseparable link between human knowing and human action. This means also that actions and their consequences are keys to cognitive/conceptual development and clarification. One of the foundational ideas within pragmatism is that the meaning of an idea or a concept is the practical consequences of the idea/concept. The meaning of a specific concept is the different actions, which we conduct, based on the belief in this concept. In his classical article "How to make our ideas clear", Peirce (1878) formulated this pragmatic principle: "Thus, we come down to what is tangible and practical as the root of every real distinction, no matter how subtle it might be; and there is no distinction of meaning so fine as to consist in anything but a possible difference of practice".

\section{Inquiry and constructive knowledge}

Dewey's concept of inquiry is central to the application of pragmatist thoughts in research. The concept is defined in the following way: "Inquiry is the controlled or directed transformation of an indeterminate situation into one that is so determinate in its constituents, distinctions and relations as to convert the elements of original situation into a unified whole" (Dewey, $1938 \mathrm{p} \mathrm{108).} \mathrm{Inquiry} \mathrm{is} \mathrm{seen} \mathrm{"as} \mathrm{a} \mathrm{natural} \mathrm{part} \mathrm{of} \mathrm{life} \mathrm{aimed} \mathrm{at} \mathrm{improving} \mathrm{our}$ condition by adaptation accommodations in the world" (Cronen, 2001, p 20). This means that an inquiry is an investigation into some part of reality with the purpose of creating knowledge for a controlled change of this part of the reality. Inquires are conducted with scientific purposes or as activities in ordinary life. Pleasants (2003) has criticized the inquiry notion just 
for this reason, that it does not give a clear demarcation line between science and non-science. However, going back to Dewey (1938), the inquiry notion of pragmatism should be seen as systematization of human beings' natural efforts to improve their situation. Inquiry should be seen as rooted in humans' ordinary initiatives for betterments, not as something distinctly separate. There are many approaches, with different labels, that are inspired by Dewey's original notion of inquiry; as e.g. action science (Argyris et al, 1985), development action inquiry (Torbert, 1999), pragmatic-systemic inquiry (Cronen, 2001), practical inquiry (Stevenson, 2005; Goldkuhl, 2008a) and pragmatic inquiry (Metcalfe, 2008).

A key idea of inquiry is thus to create knowledge in the interest of change and improvement. Dewey (1931) states that "an empiricism which is content with repeating facts already past has no place for possibility and for liberty". This means that pragmatism has an interest not only for what 'is', but also for what 'might be'; an orientation towards a prospective, not yet realised world. Pragmatism is concerned with an instrumental view on knowledge; that it is used in action for making a purposeful difference in practice. This is not only limited to prescriptions for means, but also the normative knowledge of purposes and values. Rescher (2000 p 175f) writes about this: "a pragmatism...that cares not just for the efficiency of means but for their appropriateness, which is a matter of combining a whole range of evaluative factors not efficiency and effectiveness alone but also their broader normative nature".

The knowledge character within pragmatism is thus not restricted to explanations (key form of positivism) and understanding (key form of interpretivism). Other knowledge forms such as prescriptive (giving guidelines), normative (exhibiting values) and prospective (suggesting possibilities) are essential in pragmatism. I encompass these different knowledge forms within a pragmatist epistemology as constructive knowledge. This includes also descriptive and explanatory knowledge. Such knowledge types can also be valuable in action as will be explained below.

Another pragmatist philosopher and socio-psychologist, Mead (1938) has elaborated on the action concept. He divides an action into four phases: The phases of impulse, perception, manipulation and consummation. These phases have in figure 1 been transformed into a cyclic model of human action consisting of three re-labelled phases (Goldkuhl, 2007). Mead's two first phases have been integrated (and re-labelled) into pre-assessment. The actor perceives the world and its action possibilities, and considers different courses of action. The second phase is the interventive action, i.e. when attempting to influence the world. Even in this outward-going action phase, there may be a simultaneous monitoring of the external world. The third phase is a post-assessment, when the actor perceives and assesses the outcome of the interventive action.

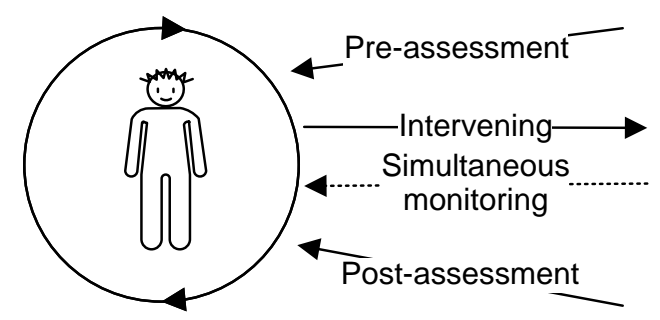

Figure 1 A cyclic model of human action (based on Goldkuhl, 2007) 
It is obvious that prescriptive and prospective knowledge is important in the interventive phase. Other knowledge forms may be useful in the two assessment phases. Normative knowledge may be used in both pre-assessment and post-assessment. Other knowledge forms such as categories, descriptions and explanations can also play important roles in perceiving and assessing the world. Different knowledge forms within constructive knowledge can be brought together within the notion of practical theory. Cronen (2001) has elaborated this notion in a pragmatic spirit based on Dewey's inquiry concept. Purposes of practical theories are described in the following way: "Practical theories should help us to see things, aspects, properties and relations which otherwise would be missed" (ibid, p 30). Appropriate conceptualisations and valid explanations are examples of such (instrumental) knowledge that can guide pre-assessment and post-assessment of the external world. Cronen describes practical theories further in the following way: "Its use should, to offer a few examples, make one a more sensitive observer of details of action, better at asking useful questions, more capable of seeing the ways actions are patterned, and more adept at forming systemic hypotheses and entertaining alternatives" (ibid). Goldkuhl (2007; 2008a) has transferred the notion of practical theory to IS and also elaborated on its possible constituents. Design theories within IS (Walls et al, 1992; Gregor \& Jones, 2007) can be seen as special kind of practical theories.

Pragmatist epistemology objects to viewing knowledge as a "copy" of reality (Dewey, 1931; Rorty, 1980). Knowledge is constructed in order to better manage existence and taking part in the world. Dewey (1931) writes: "The function of intelligence is therefore not that of copying the objects of the environment, but rather of taking account of the way in which more effective and more profitable relations with these objects may be established in the future." Pragmatism does not make a total denial of a correspondence view of truth, but claims that it is appropriate only for simple statements of small fragments of reality. For more complex epistemological objects (like vocabularies and theories), there will always be issues of utility that govern their construction and assessment (Rorty, 1980).

\section{Different kinds of pragmatism}

Pragmatism is a broad research paradigm covering many different areas e.g. knowledge, language, ethics (Rescher, 2000). In a classical article Lovejoy (1908) described 13 kinds of pragmatism. Goldkuhl (2008b) has described three types of pragmatism (and their close interrelatedness) with importance for IS research:

- Functional pragmatism

- Referential pragmatism

- Methodological pragmatism

Functional pragmatism equals what has been said about constructive knowledge above; knowledge as a basis for action. Some more comments are needed in relation to how constructive knowledge can influence and improve practice. Pragmatist research can be performed through action research (Baskerville \& Myers, 2004). In such cases there is a direct influence on engaged local practices. Scientific knowledge from pragmatist research should also be valuable for practices outside the studied ones (Goldkuhl, 2008a; Mathiassen, 2002). It is therefore important to formulate knowledge and to take other actions in order to facilitate knowledge transfer and knowledge use outside local practices. The role of local intervention in pragmatism is that it 1) is meaningful as a local improvement, but more importantly, it 2) is instrumental in creating knowledge that may be useful for local as well as general practices. Local intervention usually means that the researcher adopts a helpful and engaged attitude 
towards the local practice. The very idea of functional pragmatism is to be helpful to the world. This does however not always entail an engagement in local practices; sometimes the opposite as a distant attitude. Van de Ven (2007 p 28) describes evaluation research (as one typical example of what is referred to here as functional pragmatism) in the following way: "Evaluation from the outside is necessary because evidence-based evaluation requires comparisons of numerous cases, and because distance from any case is required for evaluation findings to be viewed as impartial and illegitimate".

Referential pragmatism is a claim to let actors, actions, action-objects, activities and practices become the primary studied objects (knowledge about actions). This follows the idea of Blumer (1969) that actions should be the primary empirical and theoretical focus; cf. quote above. This relates to pragmatist ontology, which needs to be commented upon. Dewey (1931) describes pragmatism to be based on both realist and idealist metaphysics. Pragmatism accepts things and events as existing independent of any observers, but at the same time emphasizes reason and thought as originators of elements in the external world. Goles \& Hirschheim (1999) describe pragmatism as taking a middle or dual position between positivist and interpretivist ontologies. The pragmatist position can be labelled constructive realism or symbolic realism.

Methodological pragmatism is concerned with how knowledge is created. Pragmatism emphasises the active role of the researcher in creating data and theories. Experimentation in the world is pivotal. The researcher is participating in practice in order to explore - through own actions or close observations of others' actions - the effects and success of different tactics. In action research there is a continual development, application and evaluation of knowledge and tactics which follows the basic idea of methodological pragmatism. Another important aspect is the use of different methods. Pragmatism does not take dogmatic position concerning different methods. It rather adopts a pluralist attitude (Goles \& Hirschheim, 1999). It uses the methods and method combinations that work in relation the research purpose and current empirical situation. It is however important to note that pragmatism means pluralism, but not all pluralism is pragmatic. There seems to be an emphasis in Goles \& Hirschheim (1999) for a pragmatic pluralism without considering other important pragmatic elements as, for instance, referential pragmatism.

\section{Explicit vs. implicit pragmatism}

One can claim that hitherto pragmatist thinking has played an important part in the evolution of IS research. The great interest in action research can be seen as one example of this (Baskerville \& Myers, 2004). Another example could be the growing interest in design research. There are some scholars who make their own explicit references to pragmatism as e.g. Hevner et al (2004), Cole et al (2005) and Lee \& Nickerson (2010). Design is a good example of constructive knowledge. It integrates prospective, prescriptive and normative aspects. Within IS there is a great interest in methods and models for IS development and evaluation. All these efforts can be seen as examples of creating useful knowledge for practice; that is prescriptive or in other ways constructive for practical improvements. However, in general, IS researchers, working with AR, DR and ISD methods, seldom explicitly ground their research in a pragmatist research paradigm; cf. also Mingers (2001). To conclude, IS research is implicitly pragmatist to a great extent, but explicitly much less so. No doubt there is great potential within the IS research community of becoming more explicitly aware of the paradigm grounds in pragmatism. 
The research orientations within IS mentioned above share a knowledge interest of a constructive character (i.e. functional pragmatism). Besides these orientations there exist much work with an action-orientation in theorizing (as a kind of referential pragmatism); for example building on structuration theory (Orlikowski, 1992), activity theory (Kuutti, 1996) or language action theories (Winograd \& Flores, 1986) or other social action theories (Hirschheim et al 1996; Gasson, 1998).

\section{Comparing pragmatism and interpretivism}

The descriptions of interpretivism and pragmatism above are an attempt to make ideal-typical and distinct accounts. Distinct and separate features in the two paradigms can thus be discerned. However, there are similarities between these paradigms, but this might be hard to see from these descriptions. Before making the differences even clearer, I will elaborate on some important commonalities.

There is one research school that fuses the pragmatic and interpretive together. That is the sociological school of symbolic interactionism (SI). This tradition emerged from the philosophy of American pragmatism and especially from one of its great representatives, $\mathrm{G} \mathrm{H}$ Mead (1934) but also with considerable influence from Dewey and others. Mead is seen as the originator but the scholar who coined the movement of 'symbolic interactionism' and elaborated it further was Herbert Blumer (1969). Blumer describes three foundational premises for symbolic interactionism (ibid p 2): 1) "Human beings act toward things on the basis of meanings that the things have for them", 2) "the meaning of such things is derived from, or arises out of, the social interaction that one has with one's fellows" and 3) "these meanings are handled in, and modified through, an interpretive process used by the person in dealing with the thing he encounters".

The symbolic nature of the world and its inherent constituent of interpretation lies at the core of SI. Such is also he case with the continual evolution and construction of meanings through social interaction. These are also fundamental traits of an interpretive tradition. There are obviously some common ontological assumptions behind both pragmatism and interpretivism. These can be summarized as: Meaningful action based in evolutionary social interaction. Such an ontological stance governs many pragmatist as well as interpretive studies. The affinity between pragmatism and symbolic interactionism on the one hand and interpretive traditions on the other has also been noted by Joas (1993). As mentioned, Alfred Schutz should be seen as one of the prominent scholars of the interpretive traditions. In the introduction of a book of selected writings (Schutz, 1970), the editor H Wagner points out Weber and Husserl as the two main inspirers. Several pragmatist philosophers are however also mentioned as great sources of inspiration (as James, Dewey and Mead). This does not suggest that symbolic interactionism is the only research school that brings the pragmatist and interpretive together, although it presents a good example. The use of symbolic interactionism as an example points out certain features common to the two research paradigms. If we turn to IS studies, there are, as has been stated, examples of combinations to be found. Braa \& Vidgen (1999) mention hybrid forms of interpretation and intervention. This can take the form of interpretivist action research. In such research, interpretivism is combined with functional and methodological pragmatism. There are other examples where interpretivism is combined with referential pragmatism. The interest among IS scholars to view IT usage as socio-material enactment in work practices (e.g. Leonardi \& Barley, 2008; Orlikowski, 2000; 2008 ) is one prominent example of this. It may be seen as an emerging practice turn in IS, where beliefs are no longer the single focus of interpretivist studies. The practical and 
material character of the world emerges as equally important. This is interpretivism flavoured with a speck of referential pragmatism.

In different cases of qualitative IS research it is possible to recognise the blending of the two paradigms that has taken place. One important purpose of this paper has been to clarify, in an ideal-typical fashion, each of the two paradigms for QRIS. I have described each research paradigm above and it is now time to summarize possible differences between the two paradigms based on these descriptions. The main identified differences are summarized in table 1. In regard to ontological stance it is most appropriate to label the interpretivist orientation as constructivism; see above and Orlikowski \& Baroudi (1991) and Walsham (1995). It is harder to find a suitable ontological label for pragmatism. Following the arguments presented above I label it symbolic realism. The foundation in a realistic stance towards the external world is obvious (Dewey, 1931; Rescher, 2000). It is however important to add "symbolic" to "realism", following the clear meaning-orientation in pragmatism.

Table 1 Pragmatism vs. interpretivism: ideal-typical differentiation

\begin{tabular}{|l|l|l|}
\hline & Pragmatism & Interpretivism \\
\hline Ontology & Symbolic realism & Constructivism \\
\hline Empirical focus & Actions and changes & $\begin{array}{l}\text { Beliefs (socially } \\
\text { constructed cognition) }\end{array}$ \\
\hline Type of knowledge & Constructive knowledge & Understanding \\
\hline Role of knowledge & Useful for action & Interesting \\
\hline Type of investigation & Inquiry & Field study \\
\hline Data generation & $\begin{array}{l}\text { Data through assessment } \\
\text { and intervention }\end{array}$ & Data through interpretation \\
\hline Role of researcher & Engaged in change & Engaged in understanding \\
\hline
\end{tabular}

There are apparent differences in epistemological orientations. The key character of interpretive knowledge is understanding, while in pragmatism, constructive knowledge is emphasised. The role of knowledge is here to be useful for action and change which can be contrasted to interpretivism's claim for knowledge to be interesting in itself; cf. Walsham (1993). Methodologically, pragmatism is associated with inquiry as the main type of investigation. In interpretivism, the main type of investigation would be the field study (Klein \& Myers, 1999) and data generation is conducted through interpretation. In pragmatism data are generated through and used in both assessment and intervention; see figure 1 and Mead (1938). The role of the researcher should be to promote change. Concerning interpretivism, I adhere to the view of the researcher as engaged in understanding. The two paradigms share an orientation towards understanding, but there is an important difference: In interpretivism, understanding is seen as value of its own; in pragmatism it is seen as instrumental in relation to the change of existence (Dewey, 1931). It is however important to see that understandingoriented descriptions of the world may play important roles in an action context. A good understanding of the world created in a post-assessment (cf. figure 1 above) may be useful for preventing or conducting actions.

\section{Combining pragmatism and interpretivism: a case example}

As described above, there are similarities between pragmatism and interpretivism, but there are also some important differences which have been summarized in table 1 . In research studies elements from pragmatism and interpretivism can be mixed. The reflective, qualitative 
researcher should be aware of resemblances and differences in order to make a proper research design.

In order to clarify how interpretivism and pragmatism can be combined in QRIS I will proceed by making an account of an action and design-oriented research project. This brief project description serves also to illustrate different abstract principles introduced above. The author has participated in a longitudinal e-government development concerning social welfare allowances. This project can be characterized as a practical inquiry (Goldkuhl, 2008a) including both action research and design research. The responsibility for social allowances resides within welfare boards of municipalities. It is necessary for municipal welfare officers to check the total economic situation including other allowances for an applicant. The social welfare officers need to contact different state agencies and inquire if other allowances are given to the client. In this project we developed a multi-query application that sends queries to two state agencies (the Social Insurance Agency and the Board for Study Support) and obtains immediate answers and exposes these answers to the social welfare officers. This communication was earlier mainly conducted through telephone calls and a slow batch query application.

The roles of the two participating researchers have been to actively conduct development tasks (like process modelling, information modelling, user interface design, XML schema design and also program coding) besides traditional research tasks like data collection and analysis. Data-collecting has been carried out through observation, interviewing, document analysis and IT artefact studies. This was a rather complex project with representatives from eight municipalities.

The project started with process modelling including an investigation of the existing IT systems for case handling of social allowances in the municipalities. The work routines differed between the municipalities. The process modelling had the role of an initial diagnosis (assessment); as the first step of an action research cycle (Susman \& Evered; 1978; Davison et al, 2004). It was here important to reconstruct the routines and traditions of the different municipalities. Different conceptions concerning case handling was revealed. An interpretive mode of inquiry was necessary in order to reach disclosure of differences and variations in the meaning-universes between organisations. The diagnostic process modelling was a basis for action planning (second step of action research) where a joint process between the municipalities was proposed. The next step was the design, building and implementation of the multi-query application (i.e. action taking; the third step of action research). The use of the new IT artefact among social welfare officers has been studied and evaluated by the researchers (the fourth step of action research). In order to improve further the designed artefact and put new demands on the two state agencies, the practitioners and researchers in the project have been engaged in inquiring into what was learnt (the last step in the action research cycle).

The work with process modelling, conceptual design and user interface design was theoretically informed through all parts of the combined action research and design research process. The work processes of the social welfare officers was described in terms of actions, actors, artefacts and social constructs following principles of symbolic realism (referential pragmatism). As action research there was a continual process of collaboration and $\mathrm{co}$ construction between the researchers and practitioners. Interpretations were continually verified through an open communication process. Improvements of the case handling process was proposed and implemented. There were interventions and changes both in the "social 
system" (work processes) and in the "technical system" through the introduction of new IT artefacts. This type of local intervention implies functional pragmatism.

As an action research this project has applied both functional and methodological pragmatism. Different conceptual and user interface designs have been explored through tests and assessments. The researchers have learnt through engaging in active design. The aim for constructive knowledge is however not restricted to local improvements. Based on this action and design case study, different kinds of prescriptive principles have been articulated; e.g. principles for e-infrastructure development in e-government. This means that constructive knowledge aiming for general practice is being produced.

As a design research a new artefact has been produced. This artefact is based on certain design principles ("conceptual, processual and legal transparency") which have informed the design process and have also been continually refined. This means that not only is a new artefact produced; more importantly, additional knowledge on artefact characteristics has emerged.

This project comprises several principles from pragmatist research:

- Principles of symbolic realism are applied

- Contribution to local improvements through interventions and designs

- Continual exploration and learning

- Generation of constructive knowledge aimed for general practice

It has also been "spiced with ingredients" from interpretive research:

- Focus on participants' meaning-universes and professional languages

- Interpretations of social constructs

- Co-constructive conceptual evolution between researchers and practitioners

As has been described above, this project also comprised a combination of action research and design research which should be a natural research mode in pragmatist IS research. There is a growing interest in the IS community on how to combine action research and design research (e.g. Cole et al, 2005; Järvinen, 2005; Iivari \& Venable, 2009). It is, however, beyond the purpose and scope of this paper to go into any depth of this challenging matter. Just a few comments will be given based on the case example above: There are close affinities between action research and design research since they share certain paradigmatic characteristics founded on pragmatism. Epistemologically, there is a general aim for prospective and prescriptive knowledge. Methodologically, exploration and experimentation in the world are applied in order to generate change and new knowledge. Ontologically, there is an empirical focus on actions, artefacts and actors.

\section{Conclusions}

Even if qualitative research often is associated with interpretivism, there are alternatives. As Myers \& Avison (2002b) say, qualitative research in information systems can be conducted according to interpretive, positivist and critical epistemologies. To these three research paradigms one can add pragmatism (e.g. Goles \& Hirshheim, 1999; Goldkuhl, 2004; 2008b; Marshall et al, 2005). This paper has picked out interpretivism and pragmatism as two possible and important research paradigms for qualitative research in IS. It has clarified each paradigm in an ideal-typical fashion and then performed a comparison revealing commonality 
as well as difference. The paper has thus contributed to a discussion about different QRIS paradigms and methods. From the current analysis the following alternatives for QRIS emerge:

- Pure pragmatism

- Pure interpretivism

- Combined pragmatism \& interpretivism

Pragmatism may adopt a pluralist position (Goles \& Hirshheim, 1999). This means that it uses whatever methods are suitable for the research study in question. This means that it should be possible to combine a pragmatist study with interpretive thinking and methods. There are several scholars (e.g. Braa \& Vidgen, 1999; Walsham, 1993) who describe how interpretive research can be combined with intervention and action research. The two research paradigms could thus, as has been shown above, be combined. But, if they are combined, should one be more dominant? And if so, which one should it be ? I would answer the question thus: Either interpretivism is seen as instrumental for a pragmatist study or pragmatism is seen as instrumental for an interpretive study. This means that each paradigm can be the base paradigm allowing elements from the other paradigm to be used in an instrumental and supportive fashion. It is thus possible to combine the two paradigms. Concomitantly it is necessary to acknowledge certain epistemological differences which might be hard to combine. This is because basic views on knowledge in pragmatism and interpretivism differ. It seems that as a qualitative researcher you either adopt

- an interpretive stance aiming for understanding that is appreciated for being interesting, or

- a pragmatist stance aiming for constructive knowledge that is appreciated for being useful in action.

One important imperative in pragmatism is that knowledge should make a difference in action (Dewey, 1931). What kind of differences can the argumentation of this paper imply for qualitative researchers? What will qualitative researchers do differently on the basis of what has been stated in this paper? How do the two research paradigms reviewed inform each other in practical research? These are demanding questions and I can only give some summarizing answers in this conclusion part: A pure and narrow interpretive researcher would broaden the focus besides the beliefs of people to what people actually do. A pure and narrow pragmatist researcher would broaden the focus besides the actions of people to what people think of the world. An action researcher would not only aim for local change but also for knowledge aimed for change in general practice. An action researcher would not only study local change but also describe what is going on in terms actions and beliefs. A design researcher would not only produce an artefact but also describe processes in terms of actions and beliefs. A design researcher would not only produce a local artefact but also useful design knowledge aimed for general practice.

Pragmatism has influenced IS research too a fairly large extent, albeit in a rather implicit way. The paradigmatic foundations are seldom known and explicated. This paper has aimed to contribute to further clarification of pragmatism as an explicit research paradigm for qualitative research in information systems. It should also be interpreted as a quest for having pragmatism as a possible research paradigm within IS besides other ones, as e.g. the interpretive, positivist and critical stances.

Future research may further clarify pragmatism and interpretivism and combinations thereof for qualitative research in IS. Experiences may be reported from qualitative research adopting 
one or both research paradigms with corresponding methods. This will further our knowledge on paradigms and methods for qualitative research in information systems.

\section{References}

ARENS E (1994) The logic of pragmatic thinking. From Peirce to Habermas, Humanities Press, Atlantic Highlands

ARGYRIS C, PUTNAM R, MCLAIN SMITH D (1985) Action science. Concepts, methods and skills for research and intervention, Jossey Bass, San Francisco

BASKERVILLE R (1999) Investigating information systems with action research, Communication of AIS, Vol 2

BASKERVILLE R, MYERS M (2004) Special issue on action research in information systems: making IS research relevant to practice - foreword, MIS Quarterly, Vol 28 (3), p 329-335

BASKERVILLE R, PRIES-HEJE J (1999) Grounded action research: a method for understanding IT in practice, Accounting, Management \& Information Technology, Vol 9, p $1-23$

BENBASAT I, GOLDSTEIN D, MEAD M (1987) The Case Research Strategy in Studies of Information Systems, MIS Quarterly, Vol 11 (3), p 369-386

BLUMER H (1969) Symbolic interactionism: perspective and method, University of California Press, Berkeley

BOLAND R J (1985) Phenomenology: A preferred approach to research on information systems, in Mumford E, Hirschheim R, Fitzgerald G, Wood-Harper T (Eds, 1985) Research methods in information systems, North-Holland, Amsterdam

BOLAND R J (1991) Information systems use as a hermeneutic process, in Nissen H-E, Klein $\mathrm{H}$, Hirschheim, R (Eds, 1991) Information systems research: Contemporary approaches and emergent traditions, North-Holland, Amsterdam

BRAA K, VIDGEN R (1999) Interpretation, intervention, and reduction in the organizational laboratory: a framework for in-context information system research, Accounting, Management \& Information Technology, Vol 9, p 25-47

BUTLER T (1998) Towards a hermeneutic method for interpretive research in information systems, Journal of Information Technology, Vol 13, p 285-300

CHUA W F (1986) Radical development in accounting thought, The Accounting Review, Vol $61(4), \mathrm{p}$ 601-632

COLE R, PURAO S, ROSSI M, SEIN M (2005) Being Proactive: Where Action Research meets Design Research, Proceedings of the Twenty-Sixth International Conference on Information Systems, Las Vegas, pp. 325-336

CRONEN V (2001) Practical theory, practical art, and the pragmatic-systemic account of inquiry, Communication theory, Vol 11 (1), p 14-35

DAVISON R M, MARTINSONS M G, KOCK N (2004) Principles of canonical action research, Information Systems Journal, Vol 14, p 65-86

DEWEY J (1931) The development of American pragmatism, in Dewey J (1931) Philosophy and civilization, Minton, Balch \& Co, New York

DEWEY J (1938) Logic: The theory of inquiry, Henry Holt, New York

FISHMAN D B (1999) The case for pragmatic psychology, New York University Press, New York

FITZGERALD B, HOWCROFT D (1998) Towards resolution of the IS research debate: From polarization to polarity, Journal of Information Technology, Vol 13, p 313-326 
GASSON S (1998) A Social Action Model of Situated Information Systems Design, In Proc of IFIP WG8.2 \& WG8.6 Joint Working Conference on Information Systems: Current Issues and Future Changes, Helsinki

GOLDKUHL G (2004) Meanings of pragmatism: Ways to conduct information systems research, in Proc of the $2^{\text {nd }}$ Intl Conf on Action in Language, Organisations and Information Systems (ALOIS), Linköping University

GOLDKUHL G (2007) What does it mean to serve the citizen in e-services? - Towards a practical theory founded in socio-instrumental pragmatism, International Journal of Public Information Systems, Vol 2007 (3), pp 135-159

GOLDKUHL G (2008a) Practical inquiry as action research and beyond, in Proceedings of the 16th European Conference on Information Systems, Galway

GOLDKUHL G (2008b) What kind of pragmatism in information systems research?, AIS SIG Prag Inaugural meeting, Paris

GOLES T, HIRSCHHEIM R (2000) The paradigm is dead, the paradigm is dead ... long live the paradigm: the legacy of Burell and Morgan, Omega, Vol 28, p 249-268

GREGOR S, JONES D (2007) The Anatomy of a Design Theory, Journal of AIS, Vol 8 (5), p 312-335

HEVNER A R, MARCH S T, PARK J, RAM S (2004) Design science in information systems research, MIS Quarterly, Vol 28 (1), p 75-15

HIRSCHHEIM R, KLEIN H, LYYTINEN K (1996) Exploring the intellectual structures of information systems development: a social action theoretic analysis, Accounting, Management \& Information Technology, Vol 6 (1/2), pp. 1-64

IIVARI J (2007) A Paradigmatic Analysis of Information Systems as a Design Science, Scandinavian Journal of Information Systems, Vol 19 (2), p 39-64

IIVARI J, VENABLE J (2009) Action research and design science research - Seemingly similar but decisively dissimilar, 17th European Conference on Information Systems, Verona

JOAS H (1993) Pragmatism and social theory, University of Chicago Press, Chicago

JÄRVINEN P (2005) Action research as an approach in design science, the EURAM (European Academy of Management) Conference, Munich

KLEIN H, MYERS M (1999) A set of principles for evaluating and conducting interpretive field studies in information systems, MIS Quarterly, Vol 23 (1), p 67-94

KOCK N, (Ed. 2007) Information Systems Action Research. An Applied View of Emerging Concepts and Methods, Springer

KOCK N, LAU F (2001) Information Systems Action Research: Serving Two Demanding Masters, Information Technology \& People, Vol 14 (1), p 6-11

KUUTTI K (1996) Activity theory as a potential framework for human-computer interaction research, in Nardi B A (Ed, 1996) Context and consciousness. Activity theory and human-computer interaction, MIT Press, Cambridge

LEE A (1989) Integrating positivist and interpretive approaches to organizational research, Organization science, Vol 2 (4), p 342-365

LEE A S, LIEBENAU J, DEGROSS J I (Eds, 1997) Information systems and qualitative research, Chapman \& Hall, London

LEE A, NICKERSON J (2010) Theory as a Case of Design: Lessons for Design from the Philosophy of Science, Proc of the $43^{\text {rd }}$ Hawaii International Conference on System Sciences

LEONARDI P M, BARLEY S R (2008) Materiality and change: Challenges to building better theory about technology and organizing, Information and Organization, Vol 18, p 159176 
LOVEJOY A O (1908) The Thirteen Pragmatisms, The Journal of Philosophy, Psychology and Scientific Methods, Vol 5 (1-2), pp. 5-39

MADILL A, JORDAN A, SHIRLEY C (2000) Objectivity and reliability in qualitative analysis: Realist, contextualist and radical constructionist epistemologies, British Journal of Psychology, Vol 91, p 1-20

MARSHALL P, KELDER J-A, PERRY A (2005) Social Constructionism with a Twist of Pragmatism: A Suitable Cocktail for Information Systems Research, $16^{\text {th }}$ Australasian Conference on Information Systems, Sydney

MATHIASSEN L (2002) Collaborative practice research, Information Technology \& People, Vol 15 (4), p 321-345

MEAD G H (1934) Mind, self and society, University of Chicago Press

MEAD G H (1938) Philosophy of the act, University of Chicago Press

METCALFE M (2008) Pragmatic inquiry, Journal of the Operational Research Society, Vol 59, p 1091-1099

MINGERS J (2001) Combining IS Research Methods: Towards a Pluralist Methodology, Information Systems Research, Vol 12 (3), p 240-259

MUMFORD E, HIRSCHHEIM R, FITZGERALD G, WOOD-HARPER T (Eds, 1985) Research methods in information systems, North-Holland, Amsterdam

MYERS M, AVISON D (Eds, 2002a) Qualitative research in information systems: A reader, Sage, London

MYERS M, AVISON D (2002b) An introduction to qualitative research in information systems, in Myers M, Avison D (Eds, 2002) Qualitative research in information systems: A reader, Sage, London

MYERS M, WALSHAM G (1998) Exemplifying interpretive research in information systems: An overview, Journal of Information Technology, Vol 13, p 233-234

MÅRTENSSON P, LEE A (2004) Dialogical action research at Omega corporation, MIS Quarterly, Vol 28 (3), p 507-536

NISSEN H-E, KLEIN H, HIRSCHHEIM, R (Eds, 1991) Information systems research: Contemporary approaches and emergent traditions, North-Holland, Amsterdam

ORLIKOWSKI W J (1992) The Duality of Technology: Rethinking the Concept of Technology in Organizations, Organization Science, Vol 3 (3) p 398-429

ORLIKOWSKI W J (2000) Using technology and constituting structures: a practice lens for studying technology in organizations, Organization Science, Vol 11 (4), pp 404-428

ORLIKOWSKI W J (2008) Sociomaterial Practices: Exploring Technology at Work, Organization Studies, Vol 28 (9), p 1435-1448

ORLIKOWSKI W J, BAROUDI J J (1991) Studying information technology in organizations: research approaches and assumptions, Information Systems Research, Vol 2 (1), p 1-28

PEIRCE C S (1878) How to make our ideas clear, Popular Science Monthly

PLEASANTS N (2003) A philosophy for the social sciences: Realism, pragmatism, or neither?, Foundations of Science, Vol 8, p 69-87

RESCHER N (2000) Realistic pragmatism. An introduction to pragmatic philosophy, SUNY Press, Albany

RORTY R (1980) Pragmatism, relativism and irrationalism, Proceedings and addresses of the American Philosophical Association, Vol. 53 (6), p 719-738

SCHUTZ A (1970) On phenomenology and social relations, University of Chicago Press

SHUSTERMAN (2004) Pragmatism and East-Asian thought, Metaphilosophy, Vol 35 (1/2), p 13-43

SILVERMAN D (1970) The theory of organizations, Heineman, London. 
STEVENSON C (2005) Practical inquiry/theory in nursing, Journal of Advanced Nursing, Vol 50 (2), 196-203

SUSMAN G I, EVERED R D (1978) An assessment of the scientific merits of action research, Administrative Science Quarterly, Vol 23 (4) p 582-603

THAYER H S (1981) Meaning and action. A critical history of pragmatism, Hackett Publishing, Indianapolis

TORBERT W (1999) The distinctive questions developmental action inquiry asks, Management Learning, Vol 30 (2) p 189-206

TRAUTH E M (ed, 2001) Qualitative research in IS: Issues and trends, Idea Group, Hershey

TRAUTH E M (2001b) The choice of qualitative research methods in IS, in TRAUTH E M (ed, 2001) Qualitative research in IS: Issues and trends, Idea Group, Hershey

VAN DE VEN A (2007) Engaged scholarship: A guide for organizational and social research, Oxford University Press, Oxford

WALLS J G, WIDMEYER G R, EL SAWY O A (1992) Building an information systems design theory for vigilant EIS, Information Systems Research, Vol 3 (1), pp 36-59

WALSHAM G (1993) Interpreting information system in organizations, John Wiley, Chichester

WALSHAM G (1995) Interpretive case studies in IS research: nature and method, European Journal of information systems, vol 4, p 74-81

WALSHAM G (2006) Doing interpretive research, European Journal of Information Systems, Vol 15, p 320-330

WEBER M (1978) Economy and society, University of California Press, Berkeley

WEBER R (2004) The Rhetoric of Positivism vs. Interpretivism: A Personal View, MIS Quarterly, Vol 28 (1), p iii-xii

WICKS A C, FREEMAN R E (1998) Organization studies and the new pragmatism: Positivism, anti-positivism, and the search for ethics, Organization Science, Vol 9 (2), p 123-140

WINOGRAD T, FLORES F (1986) Understanding computers and cognition: A new foundation for design, Ablex, Norwood 